\title{
Lhoba Chinese
}

National Cancer Institute

\section{Source}

National Cancer Institute. Lhoba Chinese. NCI Thesaurus. Code C158212.

A Chinese person from the Lhoba ethnic group. 